\title{
30 Years of pediatric endoscopic surgery and the challenge goes on
}

\author{
David C. van der Zee ${ }^{1} \cdot$ Maud Y. A. Lindeboom ${ }^{1} \cdot$ Stefaan H. A. Tytgat ${ }^{1}$
}

Published online: 22 February 2019

(c) Springer Nature Singapore Pte Ltd 2019

Keywords Minimal invasive surgery $\cdot$ Pediatric $\cdot$ Training $\cdot$ Center of expertise $\cdot$ Cerebral perfusion $\cdot$ NIRS

Peritoneoscopy is not new. Already in 1973, Steven Gans and George Berci described the use of the endoscope to look into the belly for diagnostic purposes, taking biopsies and even taking out a broken-off tube. The youngest patient was only 1 day old [1]. It was not until the late 1980s before endoscopic pediatric surgery followed the adult surgery to start up therapeutic goals [2, 3].

In 1994, a group of enthusiastic pioneers started the International Pediatric Endoscopy Group (IPEG). They held their first congress in Florida in 1995. Already the group realized that proper training was essential to perform safe surgery in children $[4,5]$. Initially, the means were simple with "adult" exercise boxes (Fig. 1), but with time and support from the industry animate courses could be organized to practice different procedures under the guidance of "experts" in the field (Fig. 2).

Nowadays we have the availability of virtual reality trainers, varying from simple "home boxes" to sophisticated learning centers in which all kind of procedures and emergency circumstances can be mimicked [6], and 3-D custom-designed training boxes which can be used both with animate or inanimate tissues [7]. Purpose for these training models is to acquire dexterity in minimal invasive surgery in a safe way. Does following a hands-on course make us proficient to perform complicated procedures on neonates? The answer is no. A structured curriculum with repetitive practicing and taking tests is necessary to improve our dexterity and make safe endosurgery possible [8].

What have we learned from 30 years of pediatric minimal invasive surgery? In his book "Crossing the Chasm",

David C. van der Zee

d.c.vanderzee@umcutrecht.nl

1 Center of Pediatric Upper-GI and Airway Pathology, Department of Pediatric Surgery, University Medical Center Utrecht, KE 04.140.5, P.O. Box 85090, 3508 AB Utrecht, The Netherlands
Geoffrey Moore describes the stages that have to be passed, before a new technique is generally accepted [9]. You have the "Early Market" consisting of technology enthusiasts and visionaries that adapt early to new developments in the field, but to get the new technology accepted, it has to cross the gap, the chasm. Until then the pragmatists, the conservatives, and skeptics will stay on the side line and not embrace the new technique. Translated into pediatric surgery means that different culture, older generations that have not been trained in minimal invasive surgery and, therefore, cannot lead the younger generation into the new era, or technical problems may hamper the integration of minimal invasive pediatric surgery into our society. An example is the recent publication from the Midwest Pediatric Surgery Consortium [10], consisting of 11 university centers in the USA, showing that only $8.5 \%$ of all their patients with type C esophageal atresia were operated thoracoscopically, and that, 25 years after the first case of thoracoscopic esophageal atresia repair [11]. Another issue nowadays is the ethical impact of the introduction of new techniques. The old days of "cowboys and desperado's" are over. Today we have to go through protocols, subscribed by medical societies or governments [12]. This makes setting up innovative projects more difficult. Gupta et al. [12] have set up a framework for the determination of an appropriate level of oversight. Furthermore, there is an increasing demand for concentration of care in centers of expertise. Pediatric surgery is a specialty of rare anomalies, and, therefore, a pediatric surgical department by definition is a center of expertise. However, even within the pediatric surgical specialty there are circumstances where the anomaly is so complex and the outcome is so crucial, that further concentration into specific centers is warranted $[13,14]$.

One of the major advances in adult endoscopic surgery has been the introduction of the robot $[15,16]$. However, in neonatal surgery the robot is too large to justify its use. The waiting is for robot devices that allow the use of $3 \mathrm{~mm}$ 


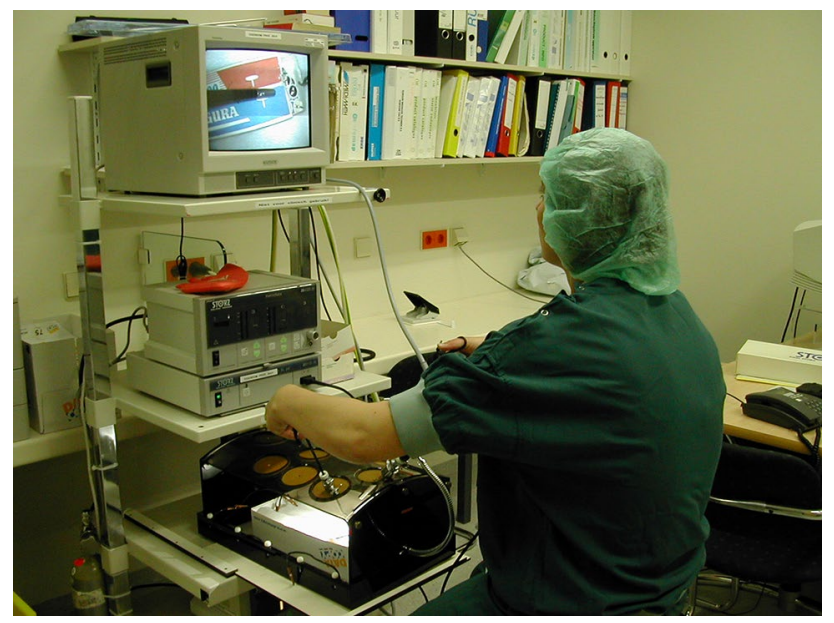

Fig. 1 Training minimal invasive surgery in a safe environment

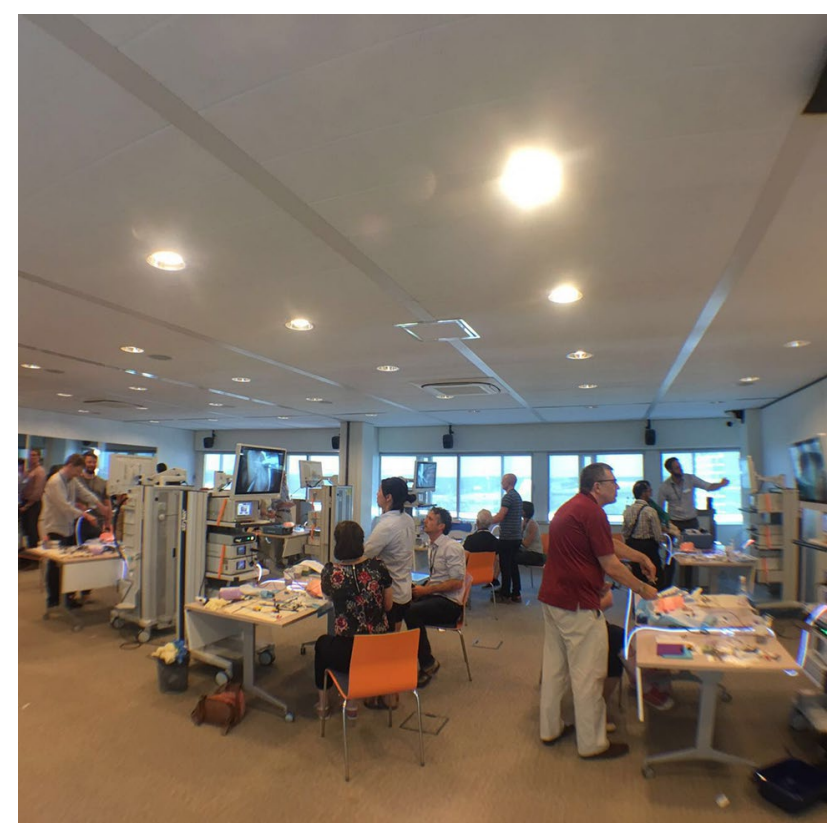

Fig. 2 Hands-on course

instruments. There are five new potential companies in the market that may facilitate future use of robotics in pediatric surgery [17]. Meanwhile other options are the development of low-cost mechanical devices for minimal invasive surgery that offer additional degrees of freedom in movement [18]. Other future developments are the use of biodegradable materials that may facilitate supportive measures without the need to remove them at a later stage [19].

There has been a recent cautioning that $\mathrm{CO} 2$ insufflation during minimal invasive surgery in neonates may have adverse effects on cerebral perfusion [20,21]. Neonates and in particular prematures lack the ability of autoregulation of cerebral perfusion in case of reduced brain perfusion pressure [22, 23]. Limitations of the London studies were the high insufflation pressures and the compromised patients involved in the study. To investigate the question, in an animal study, using $4 \mathrm{~kg}$ piglets, brain perfusion was compared using 5- and 10-mm insufflation pressures. The use of 5-mm insufflation pressure had no adverse effects of cerebral perfusion [24]. Also in a study on thoracoscopic esophageal atresia repair, insufflation was tolerated in all patients [25]. In conclusion, it is important to use low- $\mathrm{CO}_{2}$ insufflation pressures when performing minimal invasive surgery in neonates. It should be noted that also in open surgery adequate cerebral perfusion is essential [26].

In the age of high technological developments there is a danger of doctors becoming technocrats, instead of being the stronghold for anxious parents. The pediatric surgeon, not only is responsible for the proper surgical management according to the highest standards, but he or she should also be the guardian for the support of the family and its patients. Many of the congenital malformations will evolve into a lifelong disease that requires long term follow-up with transition into adult care. With this awareness more and more pediatric surgical departments offer specialized care and follow-up in multidisciplinary teams collaborating with patient societies [13, 27].

The Department of Pediatric Surgery in Utrecht has been acknowledged as a center of expertise for esophageal atresia. From merely repairing the anomaly, nowadays there is a multidisciplinary team, consisting of pediatric surgeons, pediatric ENT doctors, pediatric pulmonologists and general pediatricians, (pediatric-)gastroenterologists, neonatologists, pediatric anesthesiologists, physiotherapists and speech therapists, psychologists and dedicated nursing staff, taking care of all patients with esophageal atresia and dealing with their concomitant issues, gastroesophageal reflux disease, esophageal dysmotility and pulmonary problems, including tracheomalacia. The department has developed a thoracoscopic program for tracheomalacia. A rigorous preoperative rigid tracheobronchoscopy is the key factor to get an exact impression of the trachea and main bronchi, and may prevent future sequelae from unsuspected proximal fistulae and tracheomalacia. The department has become an international reference center for complicated esophageal atresia and tracheomalacia. Today a primary thoracoscopic posterior tracheopexy may be performed when a more than 50\% collapse of the pars membranacea is present [28], avoiding reiterative surgery to deal with the problem (Fig. 3). There is close collaboration with the patient society and a transition to adult follow-up and care in joint sessions.

30 Years of pediatric endoscopic surgery has changed from merely doing the trick to providing the whole spectrum of patient management for specific patient groups, and the challenge goes on. 


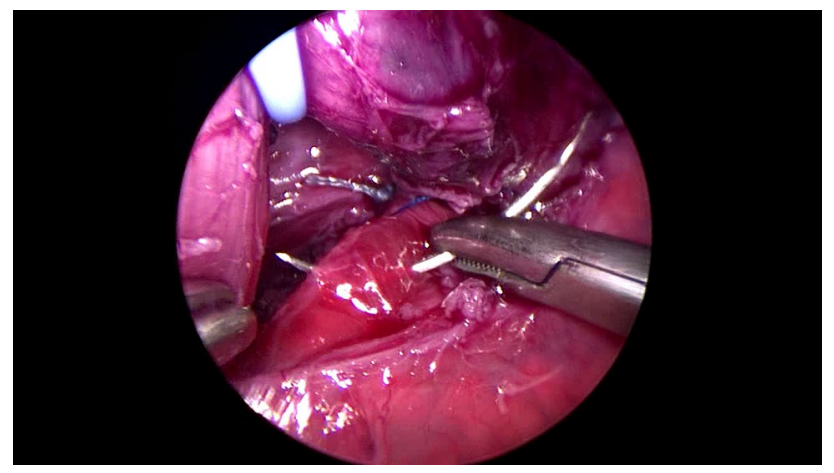

Fig. 3 Thoracoscopic posterior tracheopexy in the management of tracheomalacia

\section{References}

1. Gans SL, Berci G (1973) Peritoneoscopy in infants and children. J Pediatr Surg 8(3):399-405

2. Roshal' LM, Granikov OD, Petlakh VI, Vozdvizhenskiŭ IS, Lancheros $F$ (1985) Therapeutic laparoscopy in emergency pediatric surgery. Khirurgiia (Mosk). 10:63-66

3. Spinelli P, Pizzetti P, Lo Gullo C, Politi P, Morandi F (1988) Laparoscopy in oncological pediatrics. Pediatr Med Chir 10(1):99-101

4. Van der Zee DC (2003) Guest editorial. Prevention of complications in pediatric minimally invasive surgery. Pediatr Endosurg Innov Tech 7(1): 1-3

5. Van der Zee DC, Bax NMA (2003) The necessity for training in pediatric endoscopic surgery. Pediatr Endosurg Innov Tech $7(1): 27-31$

6. Huber T, Wunderling T, Paschold M, Lang H, Kneist W, Hansen C (2018) Highly immersive virtual reality laparoscopy simulation: development and future aspects. Int J Comput Assist Radiol Surg 13(2):281-290

7. Gause CD, Hsiung G, Schwab B, Clifton M, Harmon CM, Barsness KA (2016) Advances in pediatric surgical education: a critical appraisal of two consecutive minimally invasive pediatric surgery training courses. J Laparoendosc Adv Surg Tech A 26(8):663-670

8. Salzman David H, Wayne Diane B, Eppich Walter J et al (2017) An institution-wide approach to submission, review, and funding of simulation-based curricula. Adv Simul (Lond) 2:9

9. Geoffrey AM (2014) Crossing the chasm. Marketing and selling disruptive products to mainstream customers, 3rd edn. Harper Business, New York (9780062292988)

10. Lal DR, Gadepalli SK, Downard CD, Midwest Pediatric Surgery Consortium et al (2017) Perioperative management and outcomes of esophageal atresia and tracheoesophageal fistula. J Pediatr Surg 52(8):1245-1251

11. Lobe TE, Rothenberg SS, Waldschmidt J, Stroeder L (1999) Thoracoscopic repair of esophageal atresia in an infant: a surgical first. Pediatr Endosurg Innov Tech. 3:141-148
12. Gupta S, Muskens IS, Fandino LB et al (2018) Oversight in surgical innovation: a response to ethical challenges. World J Surg 42(9):2773-2780

13. van der Zee DC, van Herwaarden MYA, Hulsker CCC et al (2017) Esophageal atresia and upper airway pathology. Clin Perinatol 44(4):753-762

14. Madar Raya, Adini Bruria, Greenberg David et al (2018) Perspectives of health professionals on the best care settings for pediatric trauma casualties: a qualitative study. Isr J Health Policy Res. 7:12

15. Rodríguez-Sanjuán JC, Gómez-Ruiz M, Trugeda-Carrera S et al (2016) Laparoscopic and robot-assisted laparoscopic digestive surgery: present and future directions. World J Gastroenterol 22(6): 1975-2004

16. Roh HF, Nam SH, Kim JM (2018) Robot-assisted laparoscopic surgery versus conventional laparoscopic surgery in randomized controlled trials: a systematic review and meta-analysis. PLoS One 13(1):e0191628

17. https://www.charltonmorris.com/blog/detail/5-surgical-roboticcompanies-disrupting-the-market

18. https://www.nsf.gov/discoveries/disc_summ.jsp?cntn_id=19104 9

19. Morrison RJ, Hollister SJ, Niedner MF et al (2015) Mitigation of tracheobronchomalacia with 3D-printed personalized medical devices in pediatric patients. Sci Transl Med 7(285):285ra64

20. Bishay M, Giacomello L, Retrosi G (2011) Decreased cerebral oxygen saturation during thoracoscopic repair of congenital diaphragmatic hernia and esophageal atresia in infants. J Pediatr Surg 46(1):47-51

21. Bishay M, Giacomello L, Retrosi G et al (2013) Hypercapnia and acidosis during open and thoracoscopic repair of congenital diaphragmatic hernia and esophageal atresia: results of a pilot randomized controlled trial. Ann Surg 258(6):895-900

22. Brady KM, Lee JK, Kibler KK et al (2007) Continuous timedomain analysis of cerebrovascular autoregulation using nearinfrared spectroscopy. Stroke 38(10):2818-2825

23. Brady KM, Mytar JO, Lee JK et al (2010) Monitoring cerebral blood flow pressure autoregulation in pediatric patients during cardiac surgery. Stroke 41(9):1957-1962

24. Stolwijk LJ, Tytgat SH, Keunen K et al (2015) The effects of $\mathrm{CO} 2$-insufflation with 5 and $10 \mathrm{mmHg}$ during thoracoscopy on cerebral oxygenation and hemodynamics in piglets: an animal experimental study. Surg Endosc 29(9):2781-2788

25. Tytgat SH, van Herwaarden MY, Stolwijk LJ et al (2016) Neonatal brain oxygenation during thoracoscopic correction of esophageal atresia. Surg Endosc 30(7):2811-2817

26. Stolwijk LJ, Lemmers PM, Harmsen M et al (2016) Neurodevelopmental outcomes after neonatal surgery for major noncardiac anomalies. Pediatrics 137(2):e20151728

27. van der Zee DC, Tytgat SHA, van Herwaarden MYA (2017) Esophageal atresia and tracheo-esophageal fistula. Semin Pediatr Surg 26(2):67-71

28. Tytgat SHAJ, van Herwaarden-Lindeboom MYA, van Tuyll van Serooskerken ES, van der Zee DC (2018) Thoracoscopic posterior tracheopexy during primary esophageal atresia repair: a new approach to prevent tracheomalacia complications. J Pediatr Surg 53(7):1420-1423 